EGU2020-11062

https://doi.org/10.5194/egusphere-egu2020-11062

EGU General Assembly 2020

(c) Author(s) 2021. This work is distributed under

the Creative Commons Attribution 4.0 License.

\title{
Ice aprons on steep North faces: oldest surface ice in the Alps?
}

Ludovic Ravanel ${ }^{1}$, Suzanne Preunkert ${ }^{2}$, Grégoire Guillet ${ }^{1}$, Suvrat Kaushik ${ }^{1,3}$, Florence Magnin ${ }^{1}$, and Philip Deline ${ }^{1}$

${ }^{1}$ Environnements, Dynamiques et Territoires de la Montagne (EDYTEM), CNRS, Univ. Savoie Mont Blanc, France

${ }^{2}$ Institut des Géosciences de I'Environnement (IGE), CNRS, Univ. Grenoble Alpes, France

${ }^{3}$ Laboratoire d'Informatique, Systèmes, Traitement de I'Information et de la Connaissance (LISTIC), CNRS, Univ. Savoie Mont Blanc, France

Ice aprons are small but ubiquitous ice masses in high alpine ranges such as the Mont Blanc massif. Mainly present on its north faces above $3200 \mathrm{~m}$ a.s.l., they are a condition for practice of the so-called "traditional" mountaineering (now on the Intangible Cultural Heritage UNESCO list) and an indicator of the presence of permafrost in the bedrock. Most often thin $(<10 \mathrm{~m})$, these ice aprons are very sensitive to increasing air temperatures while their evolution during the recent decades suggests many coming disappearances in the short term and, consequently, a change in the permafrost thermal regime and a related increase in the rockfall occurrence.

Very few studied, ice aprons however represent an important glacial inheritance. We suggest that ice aprons are made up of very old ice, likely the oldest surface one in the Alps. In the north face of the Mont Blanc du Tacul (4248 m a.s.l.) for example, following the disappearance of the upper layers due to the increased occurrence of summer heatwaves, the ice on the present surface formed c. 2700 ago years (cold phase of Göschener I), against probably 200-300 years for the ice at the front of the Mer de Glace, the largest glacier in the French Alps. We present the ice ages acquired from five ice aprons on rock walls of the Mont Blanc massif together with ice ages from two glacier tongues of the massif (Mer de Glace and Miage Glacier). 